\title{
INVESTIGATION OF INFLUENCE OF TECHNOLOGICAL FACTORS ON CONSUMPTION PROPERTIES FORMATION IN MILK-CHERRY SMOOTHIE
}

\author{
Nadya Dzyuba \\ Department of restaurant and health food technology \\ dzyubanadya282@gmail.ru \\ Svitlana Poplavska \\ Department of restaurant and health food technology \\ ifc.technolog@gmail.com \\ Anna Palvashova \\ Department of Bioengineering and Water \\ palvashova_ai@ukr.net \\ Oksana Yemonakova \\ Department of Bioengineering and Water \\ emonakova2017@gmail.com \\ Liliya Ivashina \\ Department of tourism and hotel and restaurant business \\ Cherkasy State Technological University \\ 460 Blvd. Shevchenko, Cherkasy, Ukraine, 18006 \\ ivashinaliliya@ukr.net \\ Tatiana Kolisnichenko ${ }^{2}$ \\ ktatyna1407@gmail.com \\ Katerina Sefikhanova \\ Department of Management and Administration \\ Autonomous Subdivision "Dnipro Branch of Kyiv National University of Culture and Arts" \\ 8/92 DanilyNechaya str., Dnipro, Ukraine, 49007 \\ Anna Novik \\ anna.novik.82@ukr.net \\ Tatyana Sutkovich \\ Department of Food Technology and Restaurant Management \\ Poltava University of Economics and Trade \\ 3 Kovala str., Poltava,Ukraine, 36000 \\ tu.sutkovich@ukr.net \\ 'Odessa National Academy of Food Technologies \\ 112 Kanatna str., Odessa, Ukraine, 65039 \\ ${ }^{2}$ Department of food technology \\ Oles Honchar Dnipro National University \\ 72 Gagarina str., Dnipro, Ukraine, 49010
}

\section{Abstract}

The aim of our work is to study the structure of the food system of milk-cherry smoothie with given high consumption indices (increased content of macronutrients and easily-assimilated protein); it allows to widen the assortment of healthy beverages at enterprises of restaurant economy.

The effectiveness of functioning of restaurant economy enterprises is, in the first turn, determined by the extent, to which their strategic actions correspond to long-term market requirements. A market condition in the field of restaurant economy is a driver for developing innovative products and technologies for getting culinary products. 
At developing aerated products, the main factor of getting a high-quality one is technological regimes for getting an aerated structure. An influence of temperature and shaking time on the foam-forming ability of a food system and smoothie form stability, including milk whey, cherry juice, apple pectin and collagen hydrolysate, was studied.

It has been established, that most foam-formation (62\%) is attained at shaking smoothie under the following conditions: temperature $-10^{\circ} \mathrm{C}$, shaking time -90 seconds. The maximal number of air bubbles in smoothie has the diameter $\mathrm{d}=(0,32 \pm 0,01) \mathrm{mm}$. High multiplicity indices of the smoothie foam structure (250\%) characterize the high product stability index.

The obtained data as to the development of the technological process of getting the aerated smoothie structure give a possibility to recommend the developed technology for producing smoothie at restaurant economy enterprises.

Keywords: foam formation, rheological parameters of foams, smoothie.

DOI: $10.21303 / 2504-5695.2019 .001017$

\section{Introduction}

Today world-wide researches are directed on using a key role, played by food and beverages in supporting the life quality, in preventing and treating chronic diseases. Consumers acknowledge more and more the importance of high-quality beverages that give profit to health, in such a way resulting in increasing consumption of natural products with the proved functionality in preventing or braking the progress of degenerative diseases, caused by the oxidative stress. That is why beverages' producers are oriented at reacting to the appearing demand for natural beverages and improvement of technologies of getting them.

\section{Review of literary sources}

For today an idea that individual changes in nerve links that represent strengthening properties of food products may be connected with a risk of overeating and obesity is widespread. Studies as to revelation of reactions of the human brain to milk cocktails by the magnetic-resonance tomography were conducted. An essential positive influence of a milk cocktail on the periaqueductal gray zone of the middle brain was revealed. Thus, consumption of milk cocktails influences an answer of the middle brain and orbit-frontal cortex that give much stronger signal of the organism saturation [1].

Modern scientific data testify that milk-egg mixtures at the correspondent composition optimization have different functional properties and stable structure. A good base for producing toning beverages is secondary raw materials - buttermilk, whey and skimmed milk [2]. There was studied a possibility of using egg powder as a foam-maker for raising the food and biological value of beverages. Mathematical modeling as to getting the stable foam structure demonstrated the reasonable ratio between the milk base and egg powder as 10:1. The research results of the amino acid score demonstrated that beverages are full-value by the content of irreplaceable amino acids at the expanse of mutual enrichment with milk and egg protein.

There was developed [3] the fruit aerated smoothie, using a concentrate of natural casein, apple pectin and honey. It was proved, that foam formation and stability of the smoothie foam is higher at introducing the fruit filler in the cooled shaken solution of the natural casein concentrate at ratio between the fruit supplement and casein concentrate 2:1. The mass share of pectin, introduced for stabilizing the aerated structure, was $1 \%$.

There were studied changes at storing cocktails, obtained by mixing cherry puree with apple, pear and quince juices [4]. The content of phenol compounds, antioxidant activity and physical parameters of developed cocktails before and after storage during 6 months at $4{ }^{\circ} \mathrm{C}$ and $30{ }^{\circ} \mathrm{C}$ were studied. The obtained cocktails were attractive for consumers by a high content of polyphenols and antioxidant activity, especially ones with adding apple and quince juices. But the process of cocktail structure formation and its change at storage has not been considered in the research.

For making milk cocktails, there were used native and modified corn starch, $\lambda$-carrageenan and guar gum [5]. The structure of milk cocktails, prepared of $\lambda$-carrageenan and guar gum, preserved the best. But the sensor analysis testified that modified starch milk cocktails had the highest expected satiety indices. The obtained results testified that consumers were satisfied 
more by the satiety with dense and creamy characteristics at the very beginning of consuming cocktails. This research was directed only on studying sensor parameters, without taking into account rheological changes.

There was studied a change of sensor parameters and an increase of storage duration of the milk cocktail with banana and wheat bran at the room temperature. Among three factors wheat bran manifested the maximal influence of the increment of grey cellulose, and banana manifested a relatively low effect, whereas sugar had an inessential effect. The obtained cocktails were enriched with calcium and iron [6]

Citrus fibers were used for stabilizing the foam structure of milk cocktails. The foam-forming ability of cheese whey at pectin was higher than at using vegetable protein. The maximal concentration of oxygen and the foam stability are provided at the pectin concentration near $0,1 \%$. The sensor analysis testified that the oxygen cocktail with vegetable protein has the homogenous foamy consistence. The energetic value of the protein milk cocktail is low, but it has a high food value [7].

Work [8] describes the method of adding hydroxypropyl methylcellulose in shaken cream for intensifying its texture and shaking properties. Results [8] indicated that the increase of the amount of hydroxypropyl methylcellulose can unessentially decrease the surface protein concentration. The shaking degree of cream increases at its concentration as $0,025-0,125 \%$.

At developing aerated products, the main factor of getting high-quality one is technological regimes for getting the aerated structure. The main commodity quality parameter of smoothie is a shaken structure that can remain without changes for a long time.

The main factor of foam stability in time is stabilizing properties of surface active substances - apple pectin. Assessment criteria of the effectiveness of surface active substances are an adsorption value on the solution-gas separation limit (protein-carbohydrate system - oxygen), surface tension decrease and limit adsorption.

Thus, the study about structuring and stabilization of the aerated structure of milk cocktails is an urgent task of modern market operators that give food services.

The aim of our work is to study the structure of a food system of milk-cherry smoothie with an increased content of macronutrients and easily-assimilated protein; it allows to widen the assortment of healthy beverages at enterprises of restaurant economy.

The following tasks were set for attaining this aim:

- to study the influence of shaking time and temperature of the smoothie food system on foam-formation and dispersion;

- to study the foam stability, obtained at different temperature regimes.

\section{Materials and Methods}

Research objects were:

- collagen hydrolysate, obtained by alkaline hydrolysis of the collagen-containing fish raw material (own production by the patent of Ukraine for the useful model № 79357) - $72 \mathrm{~g}$;

- milk whey, produced by CMP № 1 Odessa city (SS 33957-2016) - 2,2 1;

- cherry juice, produced by "Vitmark-Ukraine" (SSU 7159:2010) - 2,2 1;

- apple pectin TM PEKTOWIN (SSU 6088: 2009 Ukraine) - 216 g.

The raw materials were taken according to the recipe, obtained by mathematical planning, described in [10].

The following equipment was used for conducting the researches:

- for getting the aerated structure - the blander (PHILIPS HR-1633/80, China);

- the cooling chamber (CC-0,4 MC, Mariy Erl Republic, Russia);

- the electric scales (Rotex RSK 10-P, China);

- for keeping the temperature of samples - the water bath with two working sections (WB-4 (P), Ukraine);

- for microscopy of samples - the microscope Biolam P15 (Lomo, Russia) with a digital camera-ocular ScopeTek DCM-130 E 1,3 Mp (Hangzhou Scopetek Opto-Electric Co., China).

Foam-formation of food systems was determined by the method, described in [9] 
Foam stability was estimated by the foam height after $1 \ldots .20 \times 60^{2} \mathrm{~s}$ of cylinders' keeping in rest and calculated by the formula:

$$
S=\frac{H_{f}}{H_{f s}}
$$

where $S$ - foam stability, $\% ; B_{f}$ - initial height of foam, $\mathrm{mm} ; H_{f s}$ - foam height after keeping during $1 \times 60^{2} \mathrm{~s}, \mathrm{~mm}$.

Foam multiplicity $\beta$ is a ratio between the foam volume $V_{f}$ and the solution volume $V_{s}$, needed for its creation:

$$
\beta=\frac{V_{f}}{V_{s}} \cdot 100 \%=\frac{V_{s}+V_{g}}{V_{s}} \cdot 100 \%, \mathrm{fsg},
$$

where $V_{g}$-gas volume in foam; $V_{f}$ - foam volume; $V_{s}$ - solution volume.

\section{Experimental procedures}

For developing the technology of milk-cherry smoothie, there was determined the shaking temperature influence on the foam-forming ability and foam stability of the smoothie, developed by [10].

There was studied the influence of the shaking temperature of the base on the foam-forming ability of the food system for smoothie. For conducting the study, there were chosen shaking temperatures, corresponding to the temperature of serving ready smoothie at restaurant economy enterprises. The shaking time was from $30 \mathrm{~s}$ to $120 \mathrm{~s}$ with a step in $30 \mathrm{~s}$ (Fig. 1).

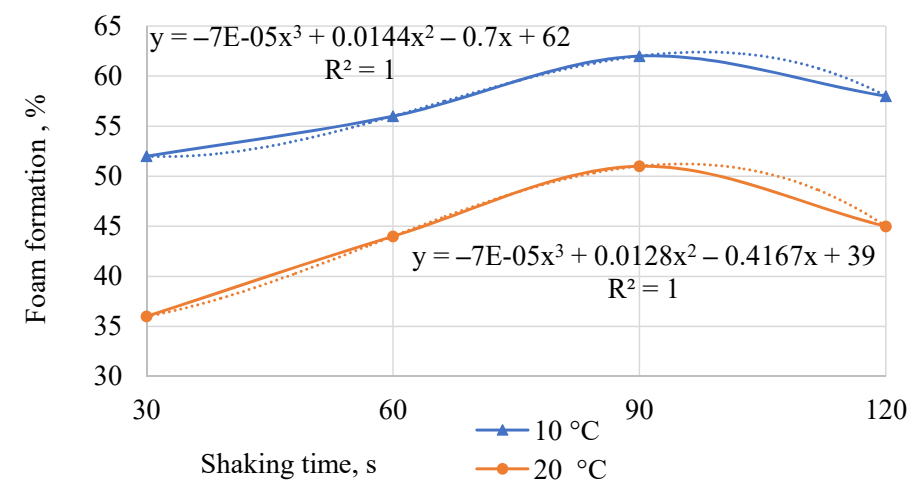

Fig. 1. Foam formation of the food system, depending on temperature

The obtained data demonstrated that the most foam formation (FF) is observed at airing at temperature $10{ }^{\circ} \mathrm{C}$. But a tendency of FF change is equal in both samples, and FF reaches its maximum at shaking during $90 \mathrm{~s}$.

In average, $\mathrm{FF}$ at temperature $20^{\circ} \mathrm{C}$ is by $17 \%$ less than at $10{ }^{\circ} \mathrm{C}$. It may be explained by chemical properties of protein and its ability to foam formation at low temperatures.

Thus, $\mathrm{FF}$ at temperature $10^{\circ} \mathrm{C}$ is $62 \%$ at shaking during $90 \mathrm{~s}$ and $58 \%$ at shaking during $120 \mathrm{~s}$. The FF decrease is connected with the fact that the food system is maximally saturated with oxygen and a film, formed on the bubbles surface begins destructing under the mechanical effect.

At shaking at $20^{\circ} \mathrm{C}$ during $90 \mathrm{~s} \mathrm{FF}$ is $51 \%$, that is by $11,76 \%$ higher than FF at $120 \mathrm{~s}$.

Such temperatures were chosen, based on requirements to restaurant economy products. Thus, cold beverages are served at $10{ }^{\circ} \mathrm{C}$, moreover milk whey and cherry juice are kept in a cooling chamber at temperature $(4 \pm 2){ }^{\circ} \mathrm{C}$. Temperature $20{ }^{\circ} \mathrm{C}$ is considered room, taking into account that products may be at cooking workshops with a high temperature threshold. Temperature must be controlled according to modern requirements of HACCP to safety of restaurant economy prod- 
ucts, but such possibilities are limited. The block of studies at $15^{\circ} \mathrm{C}$ was conducted in the scientific aspect, but this temperature was eliminated from recommendations for the technology.

According to the experimental data, the optimal shaking temperature of the food system for the foam formation process and for getting the foam with the fine porous structure must be $10{ }^{\circ} \mathrm{C}$. A conclusion may be made that this temperature, due to adsorption at interphase foamy films favors the improvement of the gas-retaining ability and intensifies the process of formation of stable oxygen foams. At that the speed of liquid, flowing from oxygen bubbles, decreases that results in decreasing capillary phenomena (diffusion and absorption of the liquid between the films decrease).

At the base temperature increase to $20{ }^{\circ} \mathrm{C}$ there is fixed the FF decrease, explained by thermal hydrocolloids, unable to strong adsorption on interphase films under such conditions.

The microphotos of the foam, created at the optimal shaking regimes of the food system, are presented on Fig. 2.

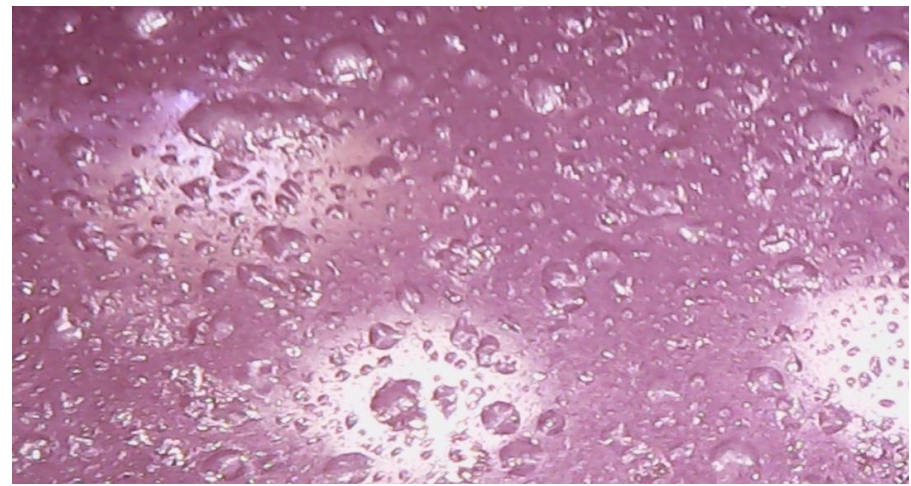

Fig. 2. Microphoto of the smoothie foam in transparent light at 400 times magnification

Fig. 2 testifies that the maximal number of oxygen bubbles has the diameter $(0.32 \pm 0.01) \mathrm{mm}$. Evenly distributed bubbles of the small size demonstrate that the obtained aerated smoothie structure is dispersed, so more stable and resistant to destruction.

Table 1 presents the research results as to the influence of the method of smoothie cooking on the foam stability and multiplicity.

Table 1

Foam stability and multiplicity

\begin{tabular}{ccc}
\hline Shaking temperature, ${ }^{\circ} \mathbf{C}$ & foam stability, min. & foam multiplicity, $\%$ \\
\hline 10 & 15 & 250 \\
20 & 11 & 210
\end{tabular}

As it can be seen on Table 1, the smoothie foam multiplicity is rather high. Thus, at getting foam at temperature $20{ }^{\circ} \mathrm{C}$, its multiplicity is in 0.84 times lower than at $10{ }^{\circ} \mathrm{C}$. The stability indices of foams, obtained at different temperatures, demonstrated that aerated food systems are stable in time and a ready product with high consumption indices may be realized at enterprises of restaurant economy.

\section{Conclusions}

Thus, it has been established, that at raising the temperature to $20{ }^{\circ} \mathrm{C}$, the foam-forming ability of the protein-berry smoothie decreases that is conditioned by the decrease of the foam films strength. Correspondingly, the surface tension increases, resulting in decreasing the mechanical stability of the surface layer of films.

The foam-forming ability of the protein-berry smoothie reaches $62 \%$ at shaking during $90 \mathrm{~s}$ at temperature $10^{\circ} \mathrm{C}$, such low value is provided by flotation of compounds that condition the sour type of milk whey and cherry juice in interphase films. The result of getting foam at $10^{\circ} \mathrm{C}$ is flotation of fatty bubbles of milk whey that, being accumulated in interphase films, prevent syner- 
esis of liquid and are retained on the surface of phases' separation at the expanse of hydrophobic properties of a lipoprotein coat.

The study of the foams multiplicity demonstrated that the foam system is polydispersed, a dispersed transformation takes place in it at the expanse of diffusion of a dispersed phase from less bubbles into more ones. For decreasing diffusion, apple pectin with stabilizing properties was added in the smoothie food system.

The offered method of cooking smoothie allows to form foams, based on milk whey with juice, enriched with collagen hydrolysate and apple pectin, activates processes of stable foam formation at the expanse of creating strong interbiopolymeric complexes of whey proteins, collagen hydrolysate and pectin.

The obtained data testified that at using sour raw materials (milk whey, cherry juice) and structure-creators (apple pectin and collagen hydrolysate), an aerated product with high stability indices and a possibility of introduction of its technology at enterprises of restaurant economy may be obtained.

This research was directed on getting smoothie with using the sour raw materials, so it would be topical to make analogous studies with using vegetable raw materials.

In further it is planned to continue the studies in the aspect of revealing critical points of the technology and decrease of the influence of negative factors. It is also planned to develop programs-preconditions of the developed technology according to HACCP international safety standards.

\section{References}

[1] Nolan-Poupart, S., Veldhuizen, M. G., Geha, P., Small, D. M. (2013). Midbrain response to milkshake correlates with ad libitum milkshake intake in the absence of hunger. Appetite, 60, 168-174. doi: https://doi.org/10.1016/j.appet.2012.09.032

[2] Ostroumova, T. L., Prosekov, A. Yu. (2006). Proizvodstvo aehrirovannyh belkovyh produktov. Izvestiya vuzov. Pishchevaya tehnologiya, 4, 52-53.

[3] Fedosova, A. N., Kaledina, M. V. (2015). Development of the functional product with honey on the basis of the concentrate of natural casein. Vestnik KrasGAU, 11, 109-115.

[4] Nowicka, P., Wojdyło, A., Teleszko, M., Samoticha, J. (2016). Sensory attributes and changes of physicochemical properties during storage of smoothies prepared from selected fruit. LWT - Food Science and Technology, 71, 102-109. doi: https://doi. org/10.1016/j.lwt.2016.03.021

[5] Morell, P., Fiszman, S. M., Varela, P., Hernando, I. (2014). Hydrocolloids for enhancing satiety: Relating oral digestion to rheology, structure and sensory perception. Food Hydrocolloids, 41, 343-353. doi: https://doi.org/10.1016/j.foodhyd.2014.04.038

[6] Karki, A., Ram, S. Y., Banerjee, J. (2015). Development of Fiber Enriched Milkshake and its Quality Evaluation. International Journal of Advanced Engineering Technology and Innovative Science (IJAETIS), 1 (2), 14-20.

[7] Montrimaitè, K., Vijole, B., Bernadeta, G. (2016). Healthy foaming agents use in oxygen cocktails. Innovative (Eco-) Technology, Entrepreneurship and Regional Development. Conference proceedings, 12-19.

[8] Zhao, Q., Zhao, M., Li, J., Yang, B., Su, G., Cui, C., Jiang, Y. (2009). Effect of hydroxypropyl methylcellulose on the textural and whipping properties of whipped cream. Food Hydrocolloids, 23 (8), 2168-2173. doi: https://doi.org/10.1016/j.foodhyd.2009.04.007

[9] Dzyuba, N., Bilenka, I., Palvashova, A., Zemlyakova, E. (2017). Study into collagen hydrolyzate applicability as a structure forming agent. Eastern-European Journal of Enterprise Technologies, 5 (11 (89)), 10-17. doi: https://doi.org/10.15587/17294061.2017.110498

[10] Dzyuba, N., Poplavska, S., Palvashova, A., Yemonakova, O., Ivashina, L., Kolisnichenko, T. et. al. (2019). Development of a policomponent composition of smuz using biotechnological and mathematical modeling and determination of its food value. Eastern-European Journal of Enterprise Technologies, 5 (11 (101)), 56-65. doi: http://doi.org/10.15587/1729-4061.2019.180755 